\title{
Connexin 43 and metabolic effect of fatty acids in stressed endothelial cells
}

\author{
Beata Kiec-Wilk • Urszula Czech • Katarzyna Janczarska • \\ Anna Knapp · Joanna Goralska • Urszula Cialowicz • \\ Maciej T. Malecki · Aldona Dembinska-Kiec
}

Received: 5 July 2011/Accepted: 5 September 2011/Published online: 24 September 2011

(C) The Author(s) 2011. This article is published with open access at Springerlink.com

\begin{abstract}
Changes in the inner mitochondrial membrane potential $(\Delta \psi)$ may lead either to apoptosis or to protective autophagy. Connexin 43 (Cx43), a gap junction protein, is suggested to affect mitochondrial membrane permeability. The aim of our study was to analyze $C \times 43$ gene expression, $\mathrm{Cx} 43$ protein localization and mitochondrial function in the human endothelial cells stressed by dietary-free fatty acids (FFA) and TNF $\alpha$. Human endothelial cells (HUVECs) were incubated with $(10-30 \mathrm{uM})$ palmitic (PA), oleic (OA), eicosapentaenoic (EPA) or arachidonic (AA) acids for $24 \mathrm{~h}$. TNF $\alpha(5 \mathrm{ng} / \mathrm{ml})$ was added at the last $4 \mathrm{~h}$ of incubation. The $C x 43$ gene expression was analyzed by the quantitative real-time PCR. The $\mathrm{Cx} 43$ protein concentrations in whole cells and in the isolated mitochondria were measured. Changes in $\Delta \psi$ and $\mathrm{Cx} 43$ localization were analyzed by flow cytometry or fluorescence microscopy. Generated ATP was measured by a luminescence assay. $\mathrm{TNF} \alpha, \mathrm{PA}$ and OA significantly decreased $\Delta \psi$, while AA $(P=0.047)$ and EPA $(P=0.004)$ increased $\Delta \psi$ value. Preincubation with EPA or AA partially prevented the $\mathrm{TNF} \alpha$-induced decrease of $\Delta \psi$. Incubation with $\mathrm{AA}$ resulted in up-regulation of the $C x 43$ gene expression. AA or PA significantly increased $\mathrm{Cx} 43$ protein content; however, presence of $\mathrm{TNF} \alpha$ in general aggravated the negative effect of FFA. Only EPA was found to increase ATP generation in HUVECs. The fatty acid-specific induction of
\end{abstract}

B. Kiec-Wilk · U. Czech · K. Janczarska - A. Knapp ·

J. Goralska - U. Cialowicz - A. Dembinska-Kiec

Department of Clinical Biochemistry, Jagiellonian University

Medical College, Krakow, Poland

B. Kiec-Wilk $(\bowtie) \cdot$ M. T. Malecki

Department of Metabolic Diseases, Jagiellonian University

Medical College, Kopernika 15 Str., 30-504, Krakow, Poland

e-mail: mbkiec@gmail.com changes in $\mathrm{Cx} 43$ expression and protein concentration as well as the normalization of $\Delta \psi$ and increase of ATP generation seem to be the separate, independent mechanisms of FFA-mediated modulatory effect in the human endothelial cells pathology.

Keywords HUVEC - FFA - Cellular stress - Cx 43 . Mitochondrial membrane potential $\cdot \mathrm{TNF} \alpha \cdot \mathrm{ATP}$

\section{Introduction}

Intercellular communication, mediated by special channels named gap junctions (GJ), plays a crucial role in the regulation of the local signals' transmission and spreading (Mroue et al. 2011). Such a local way of communication is also important in essential cellular processes such as proliferation, differentiation as well as apoptosis (Mroue et al. 2011). One of the main GJ forming proteins is connexin family (Cxs) (Mroue et al. 2011). Connexin 43 (Cx43) is expressed mainly in the heart muscle and endothelial cells (Mroue et al. 2011; Brisset et al. 2009). Several observations demonstrated important $\mathrm{Cx} 43$ role in changes that affect cellular (including endothelium) fate. Cx43 translocated from the cellular to mitochondrial membranes during ischemic stress pointing to the participation of this connexin type in the mitochondria-driven cellular response (Alex et al. 2005; $\mathrm{Li}$ et al. 2002). Decrease of $\mathrm{Cx} 43$ expression in mice resulted in much more severe and extensive necrotic changes of the myocardium during ischemic events (Schwanke et al. 2002). The above results suggest that $\mathrm{Cx} 43$ may affect some kind of a multi-protein complex that forms mitochondrial channels, which control mitochondrial inner membrane permeability. In such a case, $\mathrm{Cx} 43$ may participate in the cytoprotective effects 
similar to another mitochondrial potassium channel regulated by ATP, mitoK-ATP channel (Rodriguez-Sinovas et al. 2007).

The endoplasmic reticulum (ER) is the site of protein synthesis, their folding, their redistribution to either other intracellular compartments or elimination (Zhang 2010). All processes interfering with ER functions may result in the accumulation of unfolded proteins and induction of ER stress accompanied by toxic-free radicals generation (Zhang 2010). If an adaptation process such as lysosomal proteolysis/autophagy is insufficient, then an immunoinflammatory reaction is activated and the affected cells are eliminated by apoptosis (Zhang 2010; Tsai and Weissman 2010). Several publications suggested a functional link between ER stress and GJ in cells, i.e., myocardial and cancer ones (Zhang 2010). Cooperation of these two mechanisms may regulate cell/tissue growth (remodelling) and increase cellular resistance to stress conditions caused by hypoxia, anticancer drugs or radiation (Zhang 2010; Autsavapromporn et al. 2011; Huang et al. 2009). A correlation between ER stress and GJ dysfunction was previously shown (Huang et al. 2009). Incubation of the mesangial cells with ER stress-inducing agents resulted in a decrease of $\mathrm{Cx} 43$ expression at mRNA and protein levels due to both decreased activation of the Cx43 gene promoter as well as acceleration of the $\mathrm{Cx} 43$ protein degradation (Huang et al. 2009). Reduced amount of the Cx43 protein, due to ER stress, was demonstrated in the mesangial, human hepatoma cells as well as in human umbilical vein endothelial cells (HUVECs) (Huang et al. 2009).

Hypoxia, tumor necrosis factor alpha $(\mathrm{TNF} \alpha)$ as well as metabolic substrate overload (some free fatty acids, glucose) are known stressors affecting cellular ER and mitochondrial function (Morgan and Liu 2010; Koopman et al. 2010; Honda et al. 2005). The initial phase of cellular dysfunction is marked by changes of the inner mitochondrial membrane permeability and mitochondrial membrane potential $(\Delta \psi)$ (Morgan and Liu 2010; Koopman et al. 2010; Honda et al. 2005; Poyton et al. 2009). A decrease in $\Delta \psi$ is connected with disturbances in the respiratory chain function and increased generation of reactive oxygen species (ROS), which may lead to cell death by mechanisms of apoptosis or necrosis (Morgan and Liu 2010; Poyton et al. 2009).

ROS are important regulators of gene expression, by activating redox-sensitive transcription factors such as hypoxia inducible factor -1 (HIF-1) or nuclear factor kappa $\mathrm{B}(\mathrm{NF} \kappa \mathrm{B})$ (Gwinn and Vallyathan 2006). Cx43 gene expression is also regulated by oxidative stress (Liu et al. 2009). It is suggested that increased Cx43 expression and intensified intercellular communication induce an antiproliferative effect in the cancer cells (Liu et al. 2009).
The aim of the presented study is to analyze $C x 43$ gene expression, $\mathrm{Cx} 43$ protein localization and mitochondrial function in the human endothelial cells stressed by dietaryfree fatty acids (FFA) as well as TNF $\alpha$.

\section{Materials and methods}

\section{Cell culture}

Human umbilical vein endothelial cells (HUVECs) were isolated from umbilical cords by collagenase digestion as previously described (Jaffe et al. 1973) and were grown for 2-4 days in EBM medium (Sigma) in the presence of $2 \%$ BSA and $2 \mathrm{nM}$ of vascular endothelial growth factor (VEGF) according to a previously described protocol (Kiec-Wilk et al. 2005). The cells were incubated with nontoxic, physiological blood concentrations of the free fatty acids, $30 \mu \mathrm{M}$ of palmitic acid (PA), oleic acid (OA), eicosapentaenoic acid (EPA) or $10 \mu \mathrm{M}$ of arachidonic acid (AA) for $24 \mathrm{~h}$. To induce stress, TNF $\alpha(5 \mathrm{ng} / \mathrm{ml})$ was added to the cell culture for the last $4 \mathrm{~h}$ of incubation with each FFA (Morgan and Liu 2010; Grieger et al. 2005). The cytotoxic effect was evaluated by the lactate dehydrogenase (LDH) measurement method (CytoTox 96 NonRadioactive Cytotoxicity Assay, Promega).

Monitoring of the mitochondrial membrane potential $(\Delta \psi)$

The mitochondrial membrane potential was monitored in the cells incubated with FFA/TNF $\alpha$ by flow cytometry (FACSCanto, Becton-Dickinson) using JC-1 staining (Cossarizza 1993). The cells were then exposed to $2 \mathrm{mM}$ JC-1 dye solution (MitoProbe Assay Kit M34152, Invitrogen) and incubated in the dark for $45 \mathrm{~min}$ at $37^{\circ} \mathrm{C}$. The cells were washed and diluted in $500 \mu$ of PBS and analyzed by FACS using $488 \mathrm{~nm}$ excitation with 530/30 nm (FL1, green) and 585/42 nm (FL2, orange) emission filters.

Fluorescence signals generated by 10,000 cells were collected in a single analysis. The data were analyzed using the FacsDIVA software (Becton-Dickinson). The ratio of red/green fluorescence intensities reflected changes in the mitochondrial inner membrane potential. This ratio was the result of the $\Delta \psi$ only, without influence of other factors such as mitochondrial size, shape, or density. A known uncoupling agent, carbonyl cyanide 3-chlorophenylhydrazone $(\mathrm{CCCP}, 50 \mu \mathrm{M})$ was used as a positive control.

Intracellular ATP concentration

Following the treatment described above, a batch of $2 \times 10^{5}$ HUVECs was used to measure intracellular ATP 
concentration with the use of ATPliteTM Luminescence ATP Detection Assay System (Perkin Elmer). ATPdependent luminescent reaction with added luciferase enzyme (from Photinus pyralis) and D-luciferin was monitored (GENios TECAN Reader) in accordance to the manufacturer's protocol/guidelines. Results were calculated with Magellan 6 software as nmol ATP, then adjusted for protein content (measured by Lowry's method) and presented as nmol ATP/mg of protein.

\section{Analysis of the gene expression}

Total cellular mRNA was isolated using the TRIzol ${ }^{\circledR}$ method (Invitrogen Life Technologies) after HUVECs were incubated with the investigated factors. The analysis of $C x 43$ expression was performed using a quantitative real-time PCR (qRT-PCR) with specific primers: $\mathrm{Cx} 43-\mathrm{f}$ 5'-TCAATCACTTGGCGTGACTTCA-3', Cx43-r 5'-GCG CTCCAGTCAACCCATGT-3' ${ }^{\prime}$ and QuantiTect SYBR Green PCR (Qiagen), DNA Engine Opticon II (MJ Research). GAPDH served as the reference gene. Relative gene expression was calculated as a normalized $\mathrm{C}_{\mathrm{T}}$ difference between a sample incubated with a selected compound and its corresponding control probe; then adjusted for gene amplification efficiency relative to the expression level of the housekeeping gene, GAPDH. The formula used for calculations was according to Pfaffl et al. (2001).

\section{Detection of $\mathrm{Cx} 43$ protein distribution in HUVECs}

Connexin 43 protein was visualized by using a 1:100 dilution of primary antihuman rabbit polyclonal antibodies (Santa-Cruz) and 1:1,000 dilution of secondary anti-rabbit antibodies labeled with Alexa Fluor 594 (Invitrogen). Imaging studies were performed in 96-well plates (BD Falcon) using the BD Pathway 855 Bioimager microscope (BD Biosciences). All the imaging data were analyzed with Attovision software package.

Estimation of the Cx43 protein amount in HUVECs and isolated mitochondria

Mitochondria were isolated from HUVEC's by the Mitochondrial Isolation Kit for Cultured Cells with Halt $^{\text {TM }}$ Protease Inhibitor Cocktail, EDTA-free (PIERCE). Protein content was estimated using Cell Harvesting Buffer (Sigma) and the Bradford method. Immunoblot analyses were performed using the Laemmli method (Penna and Cahalan 2007). Protein expression of $\mathrm{Cx} 43$ was estimated using the 1:100 dilution of the specific antihuman rabbit polyclonal antibodies (Santa-Cruz) and the secondary horseradish peroxidase-conjugated anti-rabbit antibodies (NEB). Electrochemiluminescence reagent (ECL) was used for the protein final detection. Enhanced chemiluminescence, performed according to the manufacturer's instructions/guidelines (Amersham), was used to demonstrate positive bands that were visualized after exposure on a transparent medical X-ray film. Cyclophilin D (CyPD), a protein typically expressed in the mitochondria, served as the reference protein in the analysis of the isolated organelle, while actin-beta was used as the reference protein in the analysis of whole cell content.

Statistical analysis

Data were analyzed by one-way ANOVA and unpaired t-test for comparisons of quantitative variables. The cut off for statistical significance was set at $P<0.05$. The statistical analysis was performed with Statistica 6 for Windows from Statsoft.

\section{Results}

None of the used concentrations of factors (FFA, TNF $\alpha$ ) demonstrated toxic effects in the used HUVECs (results not presented).

The extent of the cellular stress was evaluated by analysis of changes in the mitochondrial membrane potential $(\Delta \psi)$ after HUVECs incubation with the investigated compounds as well as the known mitochondrial uncoupling agent, CCCP (Morgan and Liu 2010; Koopman et al. 2010; Honda et al. 2005; Poyton et al. 2009; Grieger et al. 2005). FACS analysis confirmed generation of stressful conditions by a significant decrease of $\Delta \psi$ after incubation with CCCP $(P<0.0001)$, TNF $\alpha(P=0.003)$ as well as with PA $(P=0.042)$ and OA $(P=0.002)$ (Fig. 1). On the contrary, incubation of HUVECs with polyunsaturated FFA, either EPA $(P=0.004)$ or AA $(P=0.047)$ caused significant increase of the mitochondrial membrane potential $(\Delta \psi)$ and partially ameliorated the negative effect of TNF $\alpha$ on $\Delta \psi(P=0.007$ for EPA, and $P=0.051$ for AA) (Fig. 1).

Incubation with FFA resulted in significant up-regulation of $C x 43$ gene expression following AA only $(P=0.0031) \quad$ (Fig. 2). However, pre-incubation with examined FFAs and subsequently with TNF $\alpha$ resulted in the aggravation of the TNF $\alpha$ effect. This was significant for AA and PA (Fig. 2).

The quantitative analysis of $\mathrm{Cx} 43$ protein expression under different incubation conditions by Western blot confirmed low but significant increase of $\mathrm{Cx} 43$ protein after incubation with AA $(P=0.039)$ in HUVECs and its mitochondria (Fig. 3a, b). PA $(P=0.021)$ induced elevation of $\mathrm{Cx} 43$ protein level in whole cells, but not in mitochondria (Fig. 3a, b). 


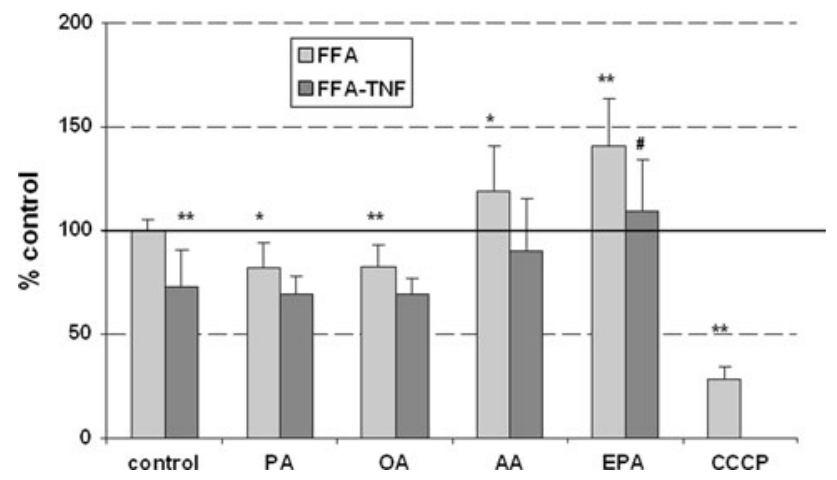

Fig. 1 The FACS quantitative analysis of changes in the inner membrane mitochondrial potential in HUVECs after their incubation with FFAs with or without TNF $\alpha$. Results are presented as ratios of red to green fluorescence signals from each sample that reflect mitochondrial metabolism following cells incubation with investigated factors, compared to the status of control sample (percent of control). $A A 0 \mu \mathrm{M}$ arachidonic acid, $O A 30 \mu \mathrm{M}$ oleic acid, EPA $30 \mu \mathrm{M}$ eicosapentoenoic acid, $P A 30 \mu \mathrm{M}$ palmitic acid, TNF $5 \mathrm{ng} / \mathrm{ml}$ $\mathrm{TNF} \alpha$, Results are mean of 3 experiments done in triplicate, $\pm \mathrm{SD}$. $P<0.05$ versus control, ${ }^{*} * P<0.003$ versus control, ${ }^{\#} P<0.004$ versus control-TNF

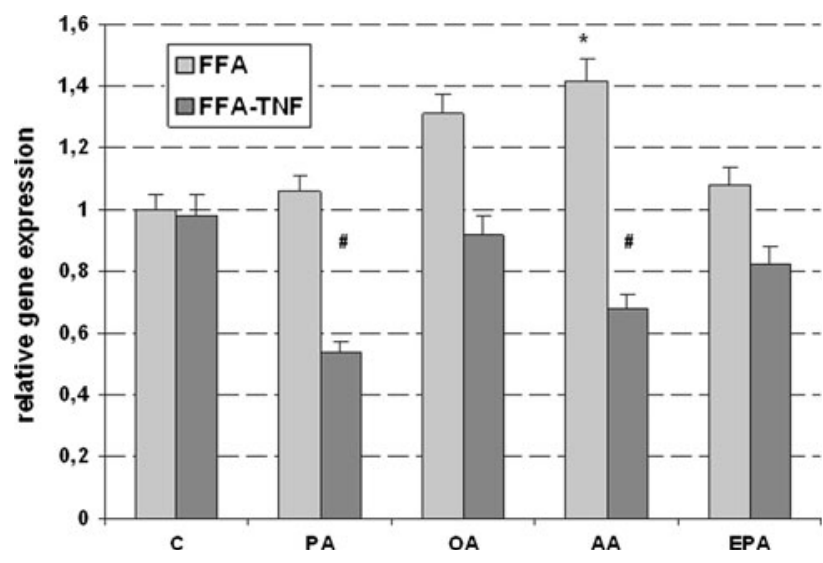

Fig. 2 The quantitative (qRT-PCR) analysis of connexin 43 gene expression after $24 \mathrm{~h}$-long incubation with investigated fatty acids or FFA and TNF $\alpha$. Results are mean of 3 experiments done in triplicate, $\pm \mathrm{SD} ; * P<0.05$ versus control; ${ }^{*} P<0.05 \mathrm{FFA}$ versus FFA + TNF. $C$ control, $A A 10 \mu \mathrm{M}$ arachidonic acid, $O A 30 \mu \mathrm{M}$ oleic acid, EPA $30 \mu \mathrm{M}$ eicosapentoenoic acid, $P A 30 \mu \mathrm{M}$ palmitic acid, TNF $5 \mathrm{ng} / \mathrm{ml}$ $\mathrm{TNF} \alpha$

The elevation of $\mathrm{Cx} 43$ protein in HUVEC cytoplasm after their incubation with AA $(P=0.043)$, OA $(P=0.027)$ and no effect of TNF $\alpha$ was also demonstrated by a quantitative analysis by fluorescence microscopy BD Pathway 855 Bioimager (Fig. 4). Incubation with FFAs followed by the addition of $\mathrm{TNF} \alpha$ resulted also in decrease of Cx43 protein, in particular after EPA $(P=0.046)$ (Fig. 4).

Saturated PA significantly decreased ATP generation in HUVECs $(P=0.038)$. A similar tendency was observed after TNF $\alpha(P=0.029)$ (Fig. 5). Preincubation with EPA significantly increased cellular ATP concentration and protected against the inhibitory effect of TNF $\alpha$ on ATP generation (Fig. 5a, b).

\section{Discussion}

There is a growing interest in search for mechanisms that would explain cellular dysfunction characteristic for the metabolic syndrome. At the molecular level, such intracellular changes are mostly related to metabolic substrate overload, cellular apoptosis, but they are also connected to the activation of cellular protective mechanisms such as endoplasmic reticulum stress and/or mitochondrial increased ATP biosynthesis, induction of autophagy (Rodriguez-Sinovas et al. 2007; Zhang 2010; Morgan and Liu 2010).

In our study, we observed in in vitro model, a decrease of the mitochondrial membrane potential $(\Delta \psi)$ induced by $\mathrm{TNF} \alpha$ as well as by nontoxic, physiological concentrations of nutritional PA and OA, which remains in agreement with other reports describing FFA and $\mathrm{TNF} \alpha$ as potent cellular stressors, also in the endothelial cells (Morgan and Liu 2010; Grieger et al. 2005). Our results indicated that the observed effects were fatty-acid specific (Shaw et al. 2007), since only polyunsaturated AA and EPA under the same conditions increased $\Delta \psi$ and ameliorated the negative effect of TNF $\alpha$.

The saturation-dependent effects of FFA on the endothelial cell functions are well known (Shaw et al. 2007; Azekoshi et al. 2010; Moreno 2009; Fuentez et al. 2001). Saturated fatty acids have been shown to cause endothelial dysfunction (Azekoshi et al. 2010), monounsaturated fatty acids exert a neutral or modestly beneficial effect (Moreno 2009), while reported results of incubation with long-chain $\mathrm{n}-3$ and n-6 polyunsaturated fatty acids give inconclusive results (Grieger et al. 2005). The effects of exogenous FFAs complexed with serum albumin appear to depend on several factors such as the type of FFA, duration of incubation, presence of pro-inflammatory cytokines (TNF $\alpha$ ), ischemia, ROS, etc. (Shaw et al. 2007). Lipotoxicity observed in the endothelial cells is characteristic for obesity and micro- and macrovascular complications associated with metabolic syndrome and diabetes (Dahlman et al. 2006).

Our results confirm that selected PUFAs can moderate endothelial cell metabolism, in response to metabolic stress condition (Suematsu et al. 2003). We also point out that incubation with the albumin-bound polyunsaturated FFA (AA and EPA) at so-called physiological concentrations, which are typically observed post-prandially in humans, is associated with beneficial elevation of the mitochondrial 
Fig. 3 The quantitative analysis of Western blot results of protein $\mathrm{Cx} 43$ concentration in HUVECs after their 24 h-long incubation with the investigated fatty acids. Presented results are mean of two experiments done in duplicate; ${ }^{*} P<0.05$. $C$ control, $A A 10 \mu \mathrm{M}$ arachidonic acid, $O A 30 \mu \mathrm{M}$ oleic acid, EPA $30 \mu \mathrm{M}$ eicosapentoenoic acid, $P A 30 \mu \mathrm{M}$ palmitic acid

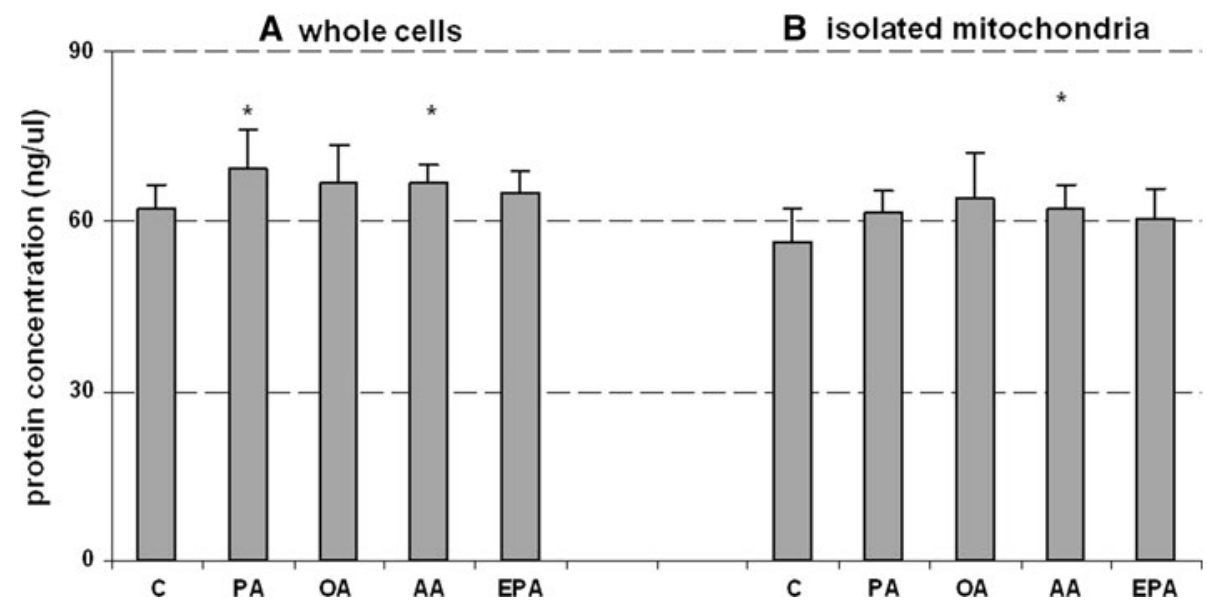

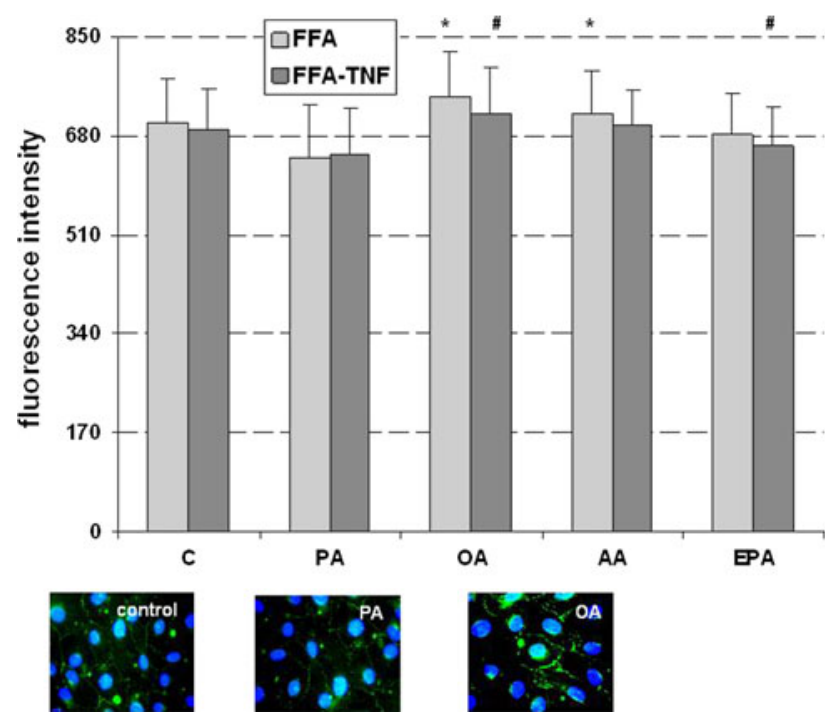

Fig. 4 The quantitative analysis of Cx43 expression and Cx43 localization in HUVECs after incubation with FFAs with or without $\mathrm{TNF} \alpha$ as visualized in fluorescent imaging study. Results are mean of 4 experiments done in triplicate; $* P<0.05$ versus control ${ }^{\#} P<0.05$ FFA versus FFA + TNF. $C$ control, $A A 10 \mu \mathrm{M}$ arachidonic acid, $O A$ $30 \mu \mathrm{M}$ oleic acid, EPA $30 \mu \mathrm{M}$ eicosapentoenoic acid, $P A 30 \mu \mathrm{M}$ palmitic acid, $T N F 5 \mathrm{ng} / \mathrm{ml}$ TNF membrane $\Delta \psi$ confirming the protective effect of the polyunsaturated FFA on the endothelial function (Sutherland et al. 2010; von Schacky 2006). However, study also demonstrates that the observed $\Delta \psi$ changes are not associated with the significant variability in ATP production (Korge et al. 2008). Increased mitochondrial generation of ATP in in vitro model was found only in the presence of EPA, but not AA. That might be one of mechanisms of positive effect of PUFAs on endothelial cells metabolism.

The observed changes in $\mathrm{Cx} 43$, the gap-junction protein, expression may also contribute to the cellular protection (Hutnik et al. 2008). Our previous results have shown that the $\mathrm{CpG}$ island methylation of $C x 43$ gene promoter contribute in the regulation of $C x 43$ expression, in HUVEC, by selected nutrients (Kiec-Wilk et al. 2011). We demonstrated that most of the investigated fatty acids up-regulated Cx43 gene expression in HUVECs, out of which AA-induced changes reached statistical significance. Analyses of the Cx43 protein concentration in the whole cells seemed to be closely related to the used FFA, since saturated PA increased the Cx43 protein content in mitochondria. Our observations appear to verify a previous
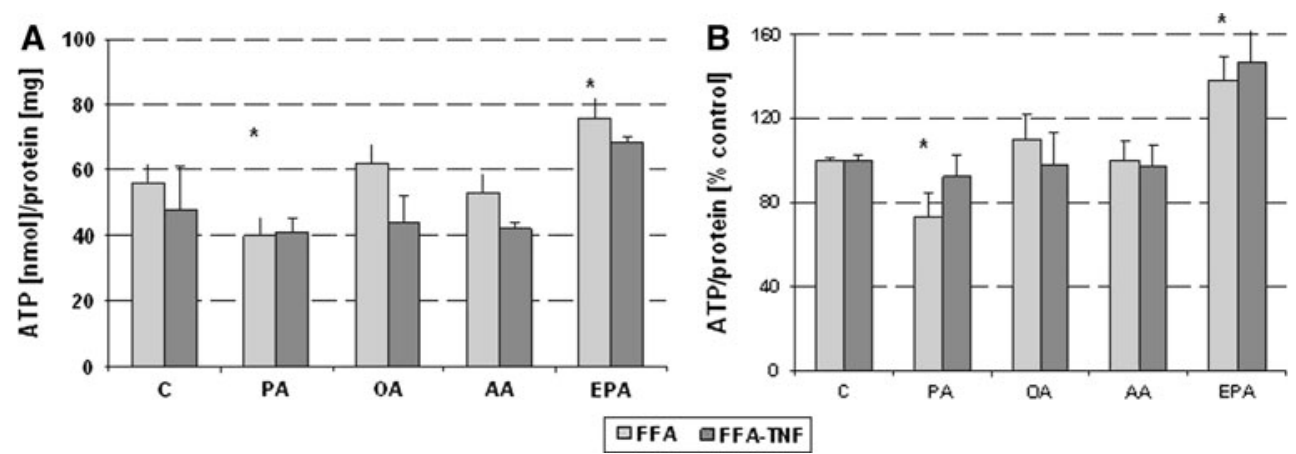

Fig. 5 Intracellular concentration of ATP in HUVECs exposed for $24 \mathrm{~h}$ to different FFAs (with or without TNF $\alpha$ for $4 \mathrm{~h}$ at the end). Data are expressed as mean of 8 experiments $+\mathrm{SD}(\mathbf{a})$ or as the $\%$ of control (b). ${ }^{*} P<0.05$ versus control, untreated cells. $C$ control, $A A$ $10 \mu \mathrm{M}$ arachidonic acid, $O A 30 \mu \mathrm{M}$ oleic acid, EPA $30 \mu \mathrm{M}$ eicosapentoenoic acid, $P A 30 \mu \mathrm{M}$ palmitic acid, $T N F 5 \mathrm{ng} / \mathrm{ml} \mathrm{TNF}$ 
report that demonstrated the $\mathrm{Cx} 43$ over-expression and its increased translocation into the mitochondria in the endothelial cells under stress conditions ( $\mathrm{Li}$ et al. 2002). On the other hand, a correlation between decreased $C x 43$ gene and protein expressions and ER stress in the cell has already been reported (Huang et al. 2009).

Overall, our study demonstrates that different FFAs may exert a variety of specific effects on the expression of this GJ gene and protein in TNF $\alpha$ stressed HUVECs. Incubation of the endothelial cells with one of the two fatty acids, AA or EPA at low, nontoxic concentrations resulted in a significant up-regulation of $C x 43$ gene expression as well as elevation of Cx43 protein content (confirmed by Western blot and confocal microscopy) in not stressed HUVECs. It is interesting to note that $\mathrm{Cx} 43$ was increased parallel to the significant rise in the mitochondrial membrane $\Delta \psi$ by AA and EPA.

The up-regulation of $\mathrm{Cx} 43$ was suggested to improve intercellular transport and normalize mitochondrial function (Schwanke et al. 2002; Rodriguez-Sinovas et al. 2007). Thus, we believe that enhancement of the mitochondrial function $(\Delta \psi)$ in HUVECs after their incubation with the selected, polyunsaturated FFAs promotes cellular trafficking and may involve Cx-mediated modification of GJ function (Rodriguez-Sinovas et al. 2007). One should notice that the positive effect of selected FFAs seems to be inhibited and in some cases inverted in stress conditions (incubation with $\mathrm{TNF} \alpha$ ).

The fatty acid-specific induction of changes in $\mathrm{Cx} 43$ expression and protein concentration as well as the normalization of $\Delta \psi$ and increase of ATP generation seem to be the separate, independent mechanisms of FFA-mediated modulatory effect in the human endothelial cells pathology.

Acknowledgments The authors would like to thank Msc Magalena Mikolajczyk and Msc Agnieszka Sliwa for excellent technical support in gathering the presented results. Project supported by the seventh framework integrated program of EU- "LipidomicNet" No 202272.

Open Access This article is distributed under the terms of the Creative Commons Attribution Noncommercial License which permits any noncommercial use, distribution, and reproduction in any medium, provided the original author(s) and source are credited.

\section{References}

Alex J, Cale ARJ, Griffin SC et al (2005) Connexins: the basis of functional coupling of myocytes guvendik. J Clin Basic Cardiol $8: 19-22$

Autsavapromporn N, de Toledo SM, Little JB, Jay-Gerin JP, Harris AL, Azzam EI (2011) The role of gap junction communication and oxidative stress in the propagation of toxic effects among high-dose $\alpha$-particle-irradiated human cells. Radiat Res 175:347-357

Azekoshi Y, Yasu T, Watanabe S, Tagawa T, Abe S, Yamakawa K, Uehara Y, Momomura S, Urata H, Ueda S (2010) Free fatty acid causes leukocyte activation and resultant endothelial dysfunction through enhanced angiotensin II production in mononuclear and polymorphonuclear cells. Hypertension 56:136-142

Brisset AC, Isakson BE, Kwak BR (2009) Connexins in vascular physiology and pathology. Antioxid Redox Signal 11:267-282

Dahlman I, Forsgren M, Sjorgen A, Nordstrom EA, Kaaman M, Naslund E, Atterstand A, Arner P (2006) Down-regulation of electron transport chain genes in visceral adipose tissue in type 2 diabetes in dependent of obesity and possibly involving tumor necrosis factor $\alpha$. Diabetes 55:1792-1799

Fuentez F, Lopez-Miranda J, Sanchez E, Sanchez F, Paez J, PazRojas E, Marin C, Gomez P, Jimenes-Pereperwz J, Ordovas J, Perez-Jimenez F (2001) Mediterranean and low fat diets improve endothelial function in hypercholestetolemic diet. Ann Intern Med 134:1115-1119

Grieger J, Keogh J, Noakes M, Foster P, Clifton P (2005) The effect of dietary saturated fat on endothelial function. Arterioscler Thromb Vasc Biol 25:1274-1279

Gwinn MR, Vallyathan V (2006) Respiratory burst: role in signal transduction in alveolar macrophages. J Toxicol Environ Health B Crit Rev 9:27-39

Honda HM, Korge P, Weiss JN (2005) Mitochondria and ischemia/ reperfusion injury. Ann NY Acad Sci 1047:248-258

Huang T, Wan Y, Zhu Y, Fang X, Hiramatsu N, Hayakawa K, Paton AW, Paton JC, Kitamura M, Yao J (2009) Downregulation of gap junction expression and function by endoplasmic reticulum stress. J Cell Biochem 107:973-983

Hutnik CM, Pocrnich CE, Liu H, Laird DW, Shao Q (2008) The protective effect of functional connexin 43 channels on a human epithelial cell line exposed to oxidative stress. Invest Ophthalmol Vis Sci 49:800-806

Jaffe EA, Nachman RL, Becker CG, Minick CR (1973) Culture of human endothelial cells derived from umbilical veins: identification by morphologic and immunologic criteria. J Clin Invest 52:2745-2756

Kiec-Wilk B, Sliwa A, Mikolajczyk M, Malecki MT, Mathers JC (2011) The $\mathrm{CpG}$ island methylation regulated expression of endothelial pro-angiogenic genes in response to $\beta$-carotene and arachidonic acid. Nutr Cancer [Epub ahead of print]

Kiec-Wilk B, Polus A, Grzybowska J, Mikolajczyk M, Hartwich J, Pryjma J, Skrzeczynska J, Dembinska-Kiec A (2005) Betacarotene stimulates chemotaxis of human endothelial progenitor cells. Clin Chem Lab Med 43:488-498

Koopman WJ, Nijtmans LG, Dieteren CE, Roestenberg P, Valsecchi F, Smeitink JA, Willems PH (2010) Mammalian mitochondrial complex I: biogenesis, regulation, and reactive oxygen species generation. Antioxid Redox Signal 15(12):1431-1470

Korge P, Honda HM, Weiss JN (2008) Effects of fatty acids in isolated mitochondria: implications for ischemic injury and cardioprotection. Am J Physiol Heart Circ Physiol 285:H259

Li H, Brodsky S et al (2002) Paradoxical overexpresion and translocation of connexin 43 in homocysteine-treated endothelial cells. Am J Physiol Heart Circ Physiol 282:2124-2133

Liu CL, Huang YS, Hosokawa M, Miyashita K, Hu ML (2009) Inhibition of proliferation of a hepatoma cell line by fucoxanthin in relation to cell cycle arrest and enhanced gap junctional intercellular communication. Chem Biol Interact 182(2-3): $165-172$

Moreno JJ (2009) Differential effects of arachidonic and eicosapentaenoic Acid-derived eicosanoids on polymorphonuclear transmigration across endothelial cell cultures. J Pharmacol Exp Ther 331:1111-1117

Morgan MJ, Liu ZG (2010) Reactive oxygen species in TNFalphainduced signaling and cell death. Mol Cells 30:1-12

Mroue RM, El-Sabban ME, Talhouk RS (2011) Connexins and the gap in context. Integr Biol (Camb) 3:255-266 
Penna A, Cahalan M (2007) Western blotting using the invitrogen NuPage Novex Bis Tris minigels. J Vis Exp 7:264

Pfaffl MW, Lange IG, Daxenberger A, Meyer HH (2001) Tissuespecific expression pattern of estrogen receptors (ER): quantification of ER alpha and ER beta mRNA with real-time RT-PCR. APMIS 109:345-355

Poyton RO, Ball KA, Castello PR (2009) Mitochondrial generation of free radicals and hypoxic signaling. Trends Endocrinol Metab $20: 332-340$

Rodriguez-Sinovas A, Cabestrero A, López D et al (2007) The modulatory effects of connexin 43 on cell death/survival beyond cell coupling. Prog Biophys Mol Biol 94:219-232

Schwanke U, Konietzka I, Duschin A et al (2002) No ischemic preconditioning in heterozygous connexin43-deficient mice. Am J Physiol Heart Circ Physiol 283:1740-1742

Shaw DI, Hall WL, Jeffs NR, Williams CM (2007) Comparative effects of fatty acids on endothelial inflammatory gene expression. Eur J Nutr 46:321-328
Suematsu N, Tsutsui H, Wen J, Kang D, Ikeuchi M, Ide T, Hayashidani S, Shiomi T, Kubota T, Hamasaki N, Takeshita A (2003) Oxidative stress mediates tumor necrosis factor-alphainduced mitochondrial DNA damage and dysfunction in cardiac myocytes. Circulation 107:1418-1423

Sutherland WH, de Jong SA, Hessian PA, Williams MJ (2010) Ingestion of native and thermally oxidized polyunsaturated fats acutely increases circulating numbers of endothelial microparticles. Metabolism 59:446-453

Tsai YC, Weissman AM (2010) The unfolded protein response, degradation from endoplasmic reticulum and cancer. Genes Cancer 1:764-778

von Schacky C (2006) A review of omega-3 ethyl esters for cardiovascular prevention and treatment of increased blood triglyceride levels. Vasc Health Risk Manag 2:251-262

Zhang K (2010) Integration of ER stress, oxidative stress and the inflammatory response in health and disease. Int J Clin Exp Med $3: 33-40$ 